\title{
APLIKASI PENCARIAN ANDROID PACKAGE (APK) BERBASIS WEB DAN MOBILE WEB DENGAN API
}

\author{
Hafsah, Heru Cahya Rustamaji, Alek Syamsudin Sriyono \\ Program Studi Teknik Informatika UPN “Veteran” Yogyakarta \\ JI. Babarsari 2 Tambakbayan 55281 Telp (0274) 485323 \\ e-mail : hafsahotha@yahoo.com
}

\begin{abstract}
With the increasing number of users and number of android apps in android market is growing rapidly, whether paid or free. In fact, free android apps in the market that are sometimes only a demo version and can not be used in the country of Indonesia as well as not all users want to buy a paid app on the market. One way to overcome this problem is to require a search engine that will find applications outside of android market spread across the internet.In this thesis, the application has been made to resolve the problem of finding the android package on the internet. The method used in the design and manufacture of this application is the method of RUP (Rational Unified Process). Application is made using Codelgniter. Applications with Codelgniter resulted in an application that can search the android package and the search results can be downloaded and installed. Terbut application has been tested on several phones with android 2.2 operating system can produce the same display.
\end{abstract}

\section{Keywords: Android, Android Application Package File, Codelgniter}

Seiring meningkatnya jumlah pengguna android dan banyaknya aplikasi android di market yang semakin berkembang pesat, baik yang berbayar maupun yang gratis. Pada kenyataannya aplikasi android gratis yang terdapat di market kadang hanya versi demo dan tidak dapat digunakan di negara Indonesia serta juga tidak semua pengguna mau membeli aplikasi yang berbayar di market. Salah satu cara untuk mengatasi permasalahan ini adalah dibutuhkan sebuah mesin pencari yang akan mencari aplikasi android diluar market yang tersebar di internet. Pada skripsi ini telah dibuat aplikasi untuk menyelesaikan masalah pencarian android package di internet. Metode yang digunakan dalam perancangan dan pembuatan aplikasi ini adalah metode RUP (Rational Unified Process). Aplikasi ini dibuat dengan menggunakan Codelgniter. Aplikasi dengan Codelgniter tersebut menghasilkan sebuah aplikasi yang dapat melakukan pencarian android package dan hasil pencariannya dapat di download serta di install. Aplikasi terbut telah diuji pada beberapa handphone dengan sistem operasi android 2.2 dapat menghasilkan tampilan yang sama.

Kata Kunci : Android, Android Application Package File, Codelgniter

\section{PENDAHULUAN}

Android kini berada dalam posisi yang baik untuk berada pada tingkat atas dalam smartphone selama dua sampai tiga tahun. Sistem operasi ini menjadi pilihan yang baik bagi para vendor smartphone karena biaya lisensinya yang lebih murah dan sifatnya yang semi open source yang dapat didistribusikan secara terbuka sehingga developer dapat bebas mengembangkan aplikasi baru didalamnya. Para developer kemudian dapat menerbitkan aplikasi yang dikembangkannya pada Android Market. Android Market adalah sebuah toko aplikasi android package (APK) berupa sebuah website yang ditujukan bagi para pengguna ponsel berbasis Android.

Dengan meningkatnya jumlah pengguna android, maka ragam aplikasi android di market pun semakin berkembang pesat. Tetapi pada kenyataannya aplikasi android gratis yang terdapat di market terkadang hanya berupa versi demo/trial atau tidak dapat digunakan di negara Indonesia. Banyak juga aplikasi android di market yang berbayar yang sangat jarang orang Indonesia untuk membeli aplikasi berbayar. Hal ini kurang diminati di indonesia selain karena faktor biaya juga karena aplikasi tersebut dibayar menggunakan paypal yang tidak semua orang mengerti cara pembayaran menggunakan paypal. Aplikasi berbayar ataupun tidak berbayar yang ada di luar market sebenarnya dapat ditemukan jika dilakukan pencarian di internet. Hanya saja kendala yang dihadapi adalah hasil pencariannya yang kurang spesifik, 
dan dengan begitu banyaknya situs yang tersedia maka ketidakefisienan waktu juga menjadi kendalanya. Untuk itu dibangun sebuah aplikasi pencari yang dapat menjadi solusi dari kendala-kendala tersebut yaitu aplikasi mesin pencari android package. Aplikasi ini memungkinkan pengguna untuk mendapatkan aplikasi android yang tersebar di internet dengan mudah dan cepat.

\section{LANDASAN TEORI}

Berikut ini beberapa landasan teori yang digunakan untuk mengembangkan aplikasi Mesin Pencari Android Package.

Android

Android adalah sistem operasi untuk telepon seluler yang berbasis Linux (Mulyadi, 2010). Android menyediakan platform terbuka bagi para pengembang buat menciptakan aplikasi sendiri untuk digunakan oleh bermacam peranti bergerak. Awalnya, Google Inc. membeli Android Inc., pendatang baru yang membuat peranti lunak untuk ponsel. Kemudian untuk mengembangkan Android, dibentuklah Open Handset Alliance, konsorsium dari 34 perusahaan peranti keras, peranti lunak, dan telekomunikasi, termasuk Google, HTC, Intel, Motorola, Qualcomm, T-Mobile, dan Nvidia.

\section{Android Application Package File}

Android Application Package File (APK) adalah paket aplikasi Android (Android Package). APK umumnya digunakan untuk menyimpan sebuah aplikasi atau program yang akan dijalankan pada perangkat Android. APK pada dasarnya seperti zip file, karena berisi dari kumpulan file. APK dapat diperoleh melalui berbagai metode, seperti menginstal sebuah aplikasi melalui \#Market, download dari sebuah situs web, atau membuat sendiri dengan bahasa Java. Jika memiliki file APK pada komputer, dan ingin menginstalnya pada handphone, maka dapat menjalankan perintah 'adb install apkname.apk' untuk install aplikasi melalui USB ke handphone (Mulyadi, 2010).

\section{Codelgniter}

Codelgniter adalah aplikasi open source berupa framework dengan model MVC (Model, View, Controller) untuk membangun website dinamis dengan menggunakan PHP (http://id.wikipedia.org/wiki/Codelgniter). Codelgniter memudahkan developer untuk membuat aplikasi web dengan cepat dan mudah dibandingkan dengan membuatnya dari awal. Codelgniter dirilis pertama kali pada 28 Februari 2006. Versi stabil terakhir 2.1.0 yang dirilis pada 28 November 2011.

\section{ANALISA DAN PERANCANGAN}

\section{Fase Inception}

Reqruitements

Requirements bertujuan untuk mendeskripsikan apa yang harus dilakukan oleh sistem. Requirements ini dilakukan pertama kali pada fase inception. Ada dua jenis requirements yang harus dilakukan untuk menghasilkan sebuah sistem yang berkualitas, yaitu kebutuhan fungsional dan kebutuhan non-fungsional.

\section{Kebutuhan Fungsional}

Aplikasi ini digunakan oleh visitor, dan admin dengan kebutuhan fungsional dari masingmasing pihak yang berbeda, diantaranya :

a. Kebutuhan untuk visitor:

Visitor dapat mencari android package terbaru yang dimuat, melihat deskripsi android package, melakukan download terhadap aplikasi yang diinginkan.

b. Kebutuhan untuk Admin :

Seorang admin memiliki hak antara lain :

a) Mengelola pengaturan dan server pada sistem

b) Melakukan login terhadap sistem.

c) Melakukan pengolahan data 
Kebutuhan Non-Fungsional

Kebutuhan Non-Fungsional dari sistem yang dibangun adalah :

1. Admin lebih bersifat sebagai pemelihara sistem dan melakukan pengolahan data.

2. Adanya antarmuka sistem yang mudah digunakan.

\subsection{Fase Elaboration}

Fase ini merupakan fase untuk pembuatan arsitektur yang menjadi dasar dari sistem. Workflow yang banyak dijalankan dalam fase ini adalah analysis dan design.

3.2.1 Analysis

Tujuan dari analysis adalah untuk mengubah kebutuhan sistem ke dalam bentuk yang menampilkan gambaran ideal dari sistem yang dibangun. Bentuk yang dimaksud adalah diagram UML.

\section{Arsitektur Sistem}

Arsitektur sistem aplikasi mobile GIS berbasis android dibuat untuk mengetahui bagaimana alur user mendapatkan informasi yang dibutuhkan. Arsitektur sistem dapat dilihat pada gambar 1 berikut ini :

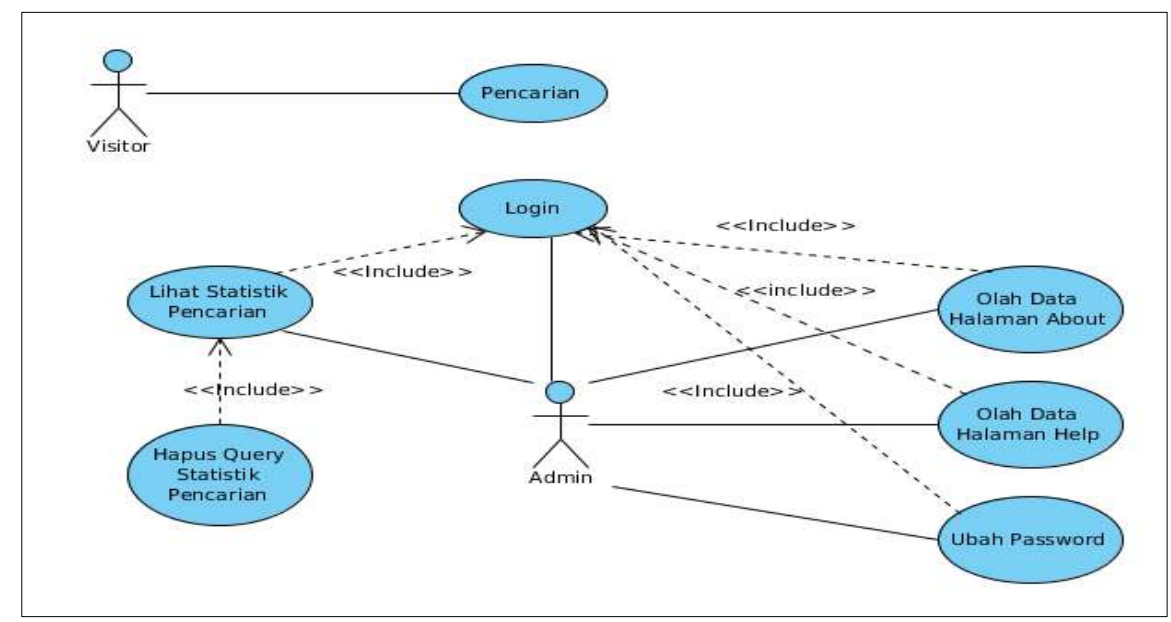

Gambar 1. Diagram Use Case

Design

Pembuatan design dibagi dalam 4 bagian yaitu pembuatan arsitektur sistem, perancangan basisdata, perancangan skema antarmuka aplikasi dan perancangan prototype antarmuka. Design dilakukan pertama kali pada fase elaboration.

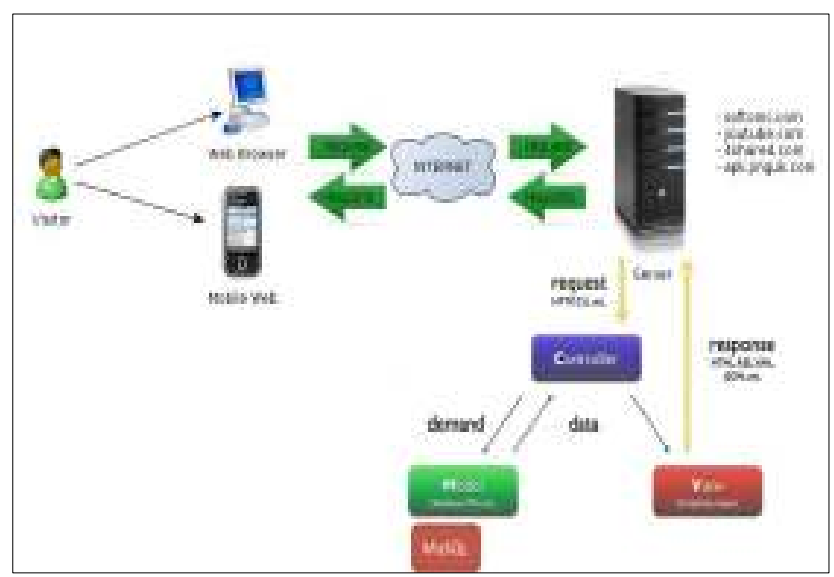

Gambar 2. Arsitektur Sistem 
Diagram Activity

1. Diagram Activity Proses Pencarian

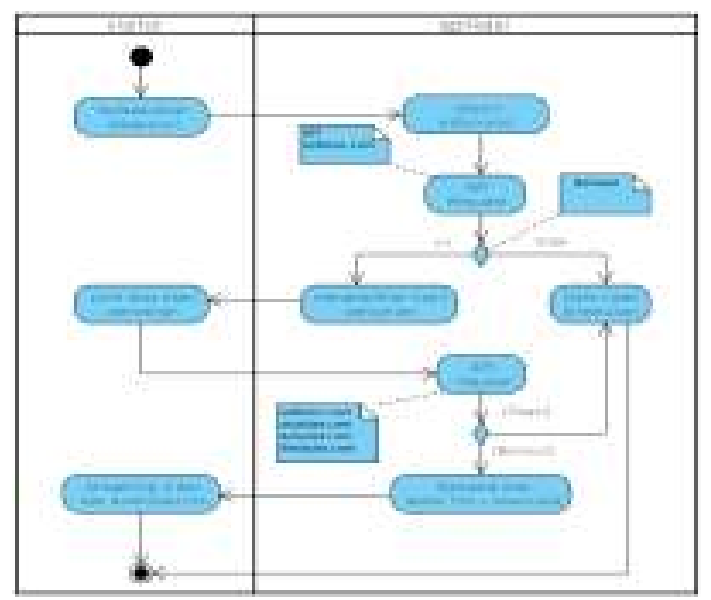

Gambar 3. Diagram Activity Proses Pencarian

2. Diagram Activity Lihat Data Statistik Pencarian

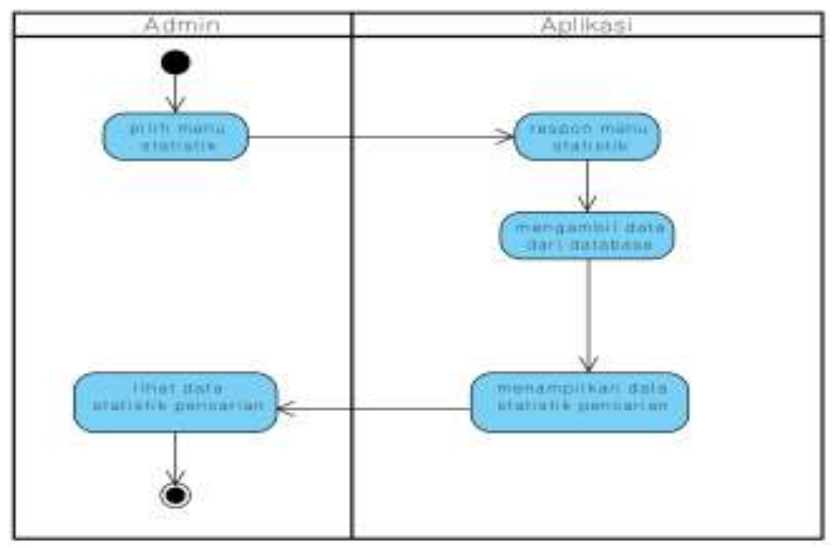

Gambar 4. Diagram Activity Lihat Data Statistik Pencarian

3. Diagram Activity Hapus Query Statistik Pencarian

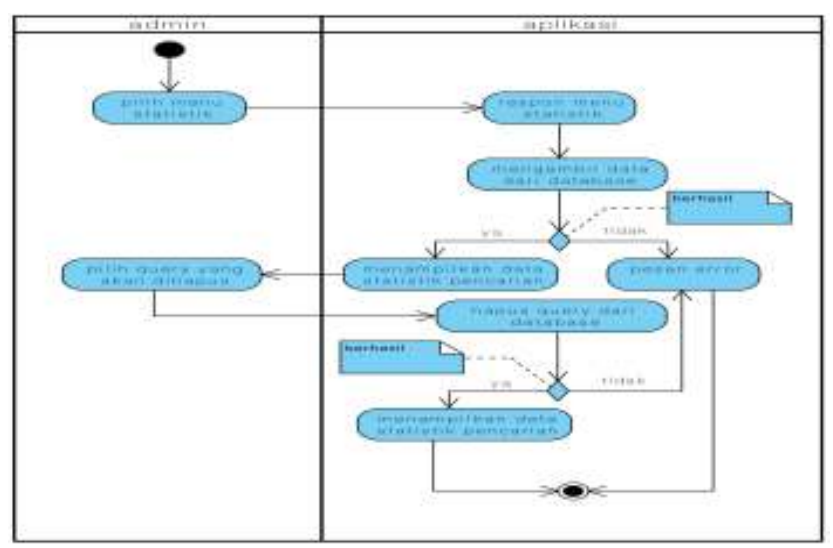

Gambar 5. Diagram Activity Hapus Query Statistik Pencarian 
4. Diagram Activity Login Admin

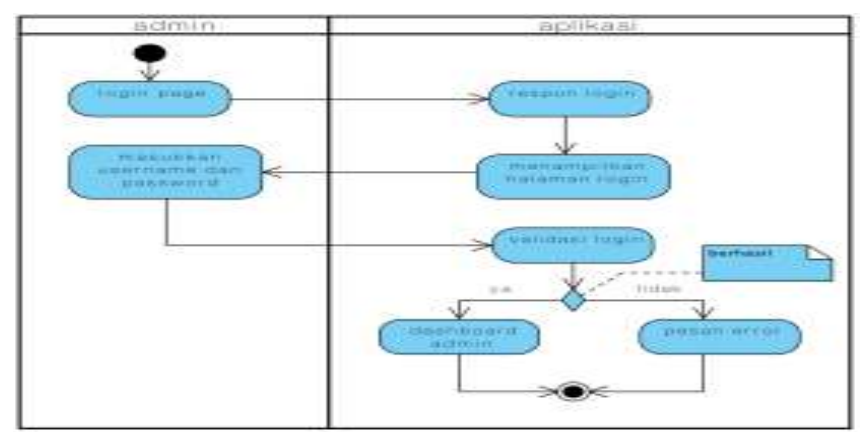

\section{IMPLEMENTASI}

Gambar 6. Diagram Activity Login Admin

Perangkat Keras yang Digunakan Untuk Membangun Aplikasi

Perangkat keras (hardware) yang digunakan saat pembuatan aplikasi dapat dilihat pada tabel berikut ini :

Tabel 1. Tabel kebutuhan perangkat keras (hardware)

\begin{tabular}{|c|l|l|} 
No & \multicolumn{1}{|c|}{ Perangkat Lunak } & \multicolumn{1}{c|}{ Keterangan } \\
\hline 1 & Laptop & Dell Inspiron 1464 \\
\hline 2 & Processor & Intel Core i3 M 330 @ 2.13GHz \\
\hline 3 & Memori & DDR2 2GB \\
\hline 4 & VGA & Intel Graphics Media Accelerator 4500 MHD \\
\hline 5 & Hard Disk & 250GB \\
\hline
\end{tabular}

4.2 Perangkat Lunak yang Digunakan Untuk Membangun Aplikasi

Perangkat lunak (software) yang digunakan didalam pembuatan aplikasi ini dapat dilihat pada tabel berikut ini :

Tabel 2. Tabel kebutuhan perangkat lunak (software)

\begin{tabular}{|c|l|l|}
\hline No & Perangkat Lunak & \multicolumn{1}{|c|}{ Keterangan } \\
\hline 1 & $\begin{array}{l}\text { Linux Ubuntu } \\
10.10\end{array}$ & Sistem Operasi \\
\hline 2 & $\begin{array}{l}\text { Netbeans IDE } \\
6.0 .1\end{array}$ & $\begin{array}{l}\text { Perangkat lunak untuk design interface user, code editor dan } \\
\text { pemodelan UML. }\end{array}$ \\
\hline 3 & LAMP & Perangkat lunak untuk pengolahan data dan web server \\
\hline 4 & Codelgniter 2.0 & Perangkat lunak sebagai framework pembuatan web \\
\hline 5 & $\begin{array}{l}\text { Open Office dan } \\
\text { yED Graph Editor }\end{array}$ & Perangkat lunak sebagai pengolah kata dan pembuatan interface. \\
\hline
\end{tabular}

4.3 Tampilan Aplikasi

Tampilan Halaman Utama dapat dilihat pada gambar 7 berikut :

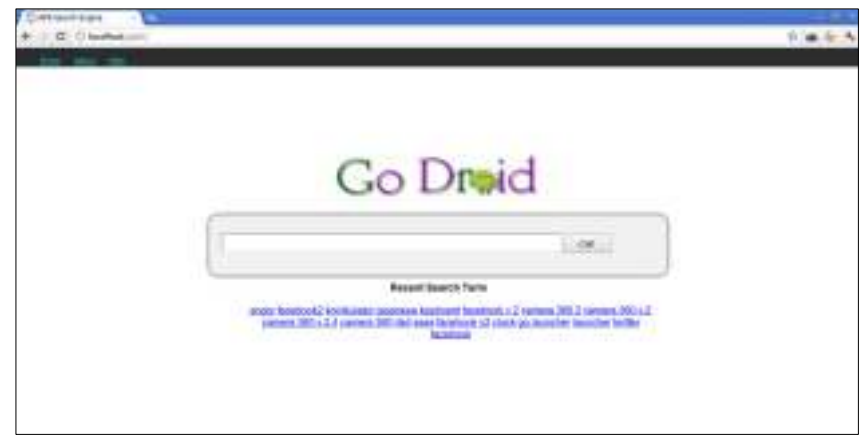

Gambar 7. Halaman Utama 
Tampilan Halaman Hasil Pencarian halaman dapat dilihat pada gambar 8 berikut :

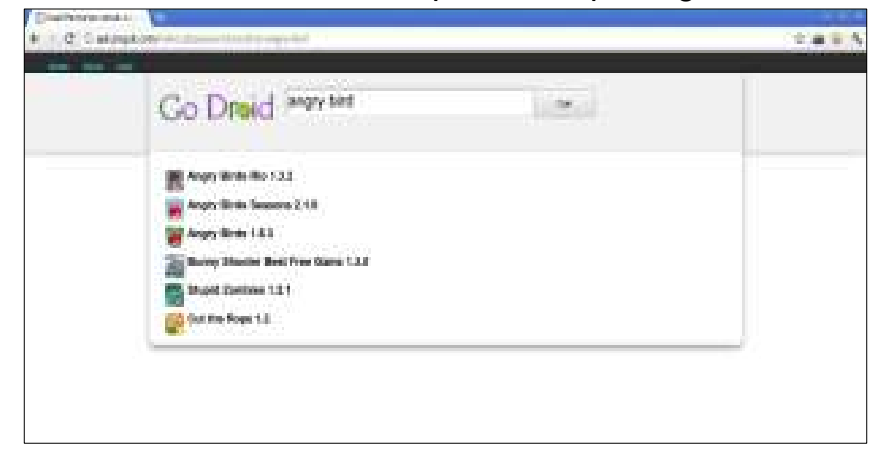

Gambar 8. Halaman Hasil Pencarian

Tampilan Halaman Detail Hasil Pencarian dapat dilihat pada gambar 9 berikut :

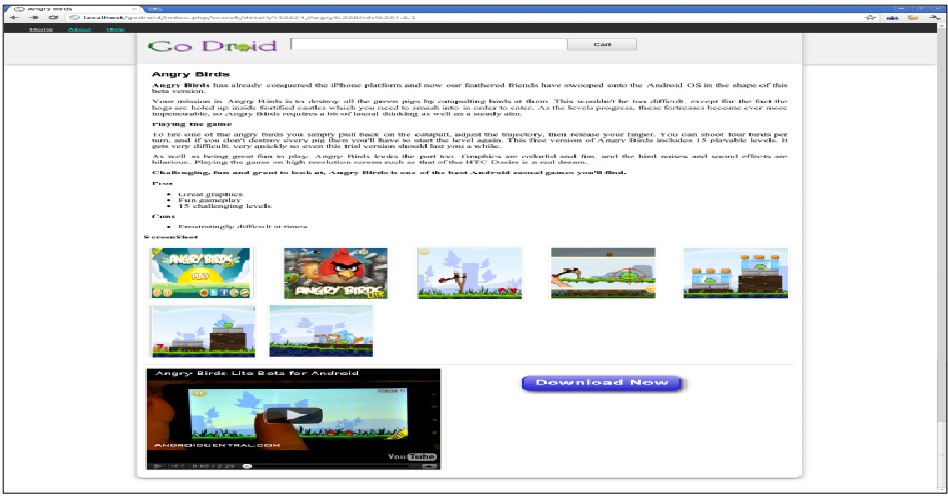

Gambar 9. Halaman Detail Hasil Pencarian

\section{KESIMPULAN}

Berdasarkan penelitian yang telah dilakukan, maka dapat disimpulkan telah berhasil dibangun sebuah aplikasi mesin pencari android package untuk membantu user dalam pencarian android package diluar market.

\section{DAFTAR PUSTAKA}

Hartono ,Jogiyanto , 2005, Analisis \& Desain Sistem Informasi Pendekatan Terstruktur Teori dan Praktek Aplikasi Bisnis, Andi, Yogyakarta.

Mulyadi, 2010, Membuat Aplikasi Untuk Android,Multimedia Center publishing, Yogyakarta.

Nuryadin, Ruslan, 2005, Panduan Menggunakan Mapserver, Informatika, Bandung.

Prahasta, Eddy, 2001, Konsep-Konsep Dasar Sistem Informasi Geografis, Informatika, Bandung.

Prahasta, Eddy, 2002, Sistem Informasi Geografis Tutorial Arcview, Informatika, Bandung.

Riyanto, dkk, 2009, Pengembangan Aplikasi Sistem Informasi Geografis, Gava Media, Yogyakarta.

Riyanto, 2010, Sistem Informasi Geografis Berbasis Mobile, Gava Media, Yogyakarta.

Schmuller, Joseph, 1999, Teach Yourself UML in 24 Hours, Sams Publishing, Indianapolis.

Suhendar, A., 2002, Visual Modeling Menggunakan UML dan Rational Rose, Informatika, Bandung.

Usman, Ferdinan, dkk, 2007, Teori \& Aplikasi Open Source GIS menggunakan Map Windows, ANDI,Yogyakarta.

Veness, C., 2010, Calculate distance, bearing and more between Latitude/Longitude points,

http://www.movabletype.co.uk/scripts/latlong.html, 24 Januari 2012.

Wardana, 2010, Menjadi Master Php dengan Framework Codeigniter, PT Elex Media Komputindo, Jakarta.

http://www.mcscv.com/produk detail.php?id=defadm\&pid=pengertian-jenis-OS-Android\&pageid=ViewFreeTopikDetailArea:pengertian-ienis-OS-Android, 3 Mei 2011. 